\title{
Erratum to: Using Fractal Dimension to Assess Robot Operator Skill in a Search Task
}

\author{
Jeffrey D. Craighead
}

Published online: 21 April 2011

(C) Springer Science+Business Media B.V. 2011

\section{Erratum to: J Intell Robot Syst DOI 10.1007/s10846-010-9530-8}

The author would like to note that the caption for Fig. 1 should have cited the reference "Phillips, F. and Voshell, M. (2006). A novel metric for evaluating human-robot navigation performance. In: RTA/HFM symposium: human factors of uninhabited military vehicles as force multipliers, Biarritz, France, 9-11 October 2006." Figure 1 was adapted from a figure appearing in this work. A citation for this work should also appear in Section 2.

The online version of the original article can be found at http://dx.doi.org/10.1007/s10846-010-9530-8.

J. D. Craighead $(\varangle)$

HSR\&D/RR\&D Center of Excellence, James A. Haley Veterans' Hospital, 8900 Grand Oak Circle, Tampa, FL 33637, USA

e-mail: jeffcraighead@gmail.com 